\title{
METODOLOGIAS ATIVAS DE APRENDIZAGEM: RELATO DE UMA AULA PRÁTICA NA FORMAÇÃO CONTINUADA DE TUTORES E PROFESSORES NO EAD
}

\author{
BALNEÁRIO CAMBORIÚ/SC JUNHO/2018
}

\author{
Sigmundo Preissler Junior \\ - Avantis - sigmundo.preissler@avantis.edu.br \\ André Gobbo \\ - Avantis - andre.gobbo@avantis.edu.br \\ Gabriela Piske \\ - Avantis - gabriela.piske@avantis.edu.br \\ Tipo: Relato de Experiência Inovadora (EI) \\ Categoria: Métodos e Tecnologias \\ Setor Educacional: EDUCAÇÃO SUPERIOR
}

\begin{abstract}
RESUMO
A atual realidade da educação caminha em conjunto com as mudanças da sociedade em relação ao amplo e fácil acesso às tecnologias, principalmente a internet. A geração de estudantes de hoje tem a sua disposição o conhecimento na palma da mão, visto a autonomia da busca do conhecimento na web e a rapidez que isso ocorre. Tais impactos disruptivos provocam os seguintes questionamentos que motivam esse estudo: Na sala de aula, continuaremos a investir no ensino tradicional, tendo o professor como disseminador do conhecimento e repassador único das informações? Será que a tecnologia não pode ser usada a favor, como já vem ocorrendo no Ensino a Distância? Diante dessa necessidade encontrada, uma faculdade do Estado de Santa Catarina tem investido na formação de seus docentes acerca do uso de metodologias ativas de aprendizagem nas aulas tanto dos cursos presenciais quanto dos a distância. Nesse sentido, o presente estudo apresenta um relato de experiência de uma aula prática com os professores, na qual se fez o uso de Rotação por Estações, uma metodologia ativa que se mostrou como uma importante estratégia para provocar nas práxis dos docentes, em sala de aula.
\end{abstract}

Palavras-chave: Formação docente. Metodologias ativas de aprendizagem. Rotação por estações. 


\section{Introdução}

Há muito se discute sobre o papel da escola e o seu formato de ensino-aprendizagem, os quais se estendem a todas as esferas educacionais, seja na educação formal, seja no informal. Afinal, até que ponto a exposição do conteúdo, com o professor à frente dos alunos, enfileirados, ainda pode ser entendida como a melhor prática pedagógica? Ademais: $O$ ensino tradicional continua apresentando os resultados esperados na formação dos indivíduos?

Vive-se, atualmente, um advento que tem interferido significativamente na sociedade como um todo e na globalização. É a era de constantes e ubíquas mudanças tecnológicas, o que faz com que crianças desde cedo tenham acesso ao celular e, por meio dele, crescem conectados à rede internacional de computadores. Frente a essa realidade, pode-se afirmar que tanto essa quanto as futuras gerações não compreendem como seria o mundo sem a internet e desprovidos dos recursos digitais.

Neste mesmo sentido, gerações anteriores estão cada vez mais adeptas à web e a tudo que a tecnologia oferece. Mesmo que indivíduos tenham nascidos em épocas nas quais o computador era restrito ao uso comercial, a evolução tecnológica, com o passar dos anos, chegou ao cotidiano da maioria. Desta forma, a adaptação a esse mundo digital tem sido necessária e/ou desejada pela maioria, afinal, ter um smartphone, com diversos aplicativos para as mais variadas funcionalidades, virou algo comum e de anseio a todos os estratos sociais.

Diante o exposto, torna-se nítido que a educação também sofra interferência dessa era, o que é possível dizer que se é premente provocar mudanças de paradigmas, práticas e recursos que colocam em discussão sobre o uso das tecnologias em sala de aula e, principalmente, acerca dessas gerações que já habitam a escola ou que, num futuro próximo, serão o público escolar. Portanto, um novo desafio está lançado aos docentes: ou se mantém as estratégias utilizadas há séculos ou adequa o processo de ensinoaprendizagem ao que de novo existe na atualidade.

A isso, Moran (2015, p. 16) destaca que "[...] os métodos tradicionais, que privilegiam a transmissão de informações pelos professores, faziam sentido quando o acesso à informação era difícil". Diferentemente do que ocorre com o advento das novas ferramentas tecnológicas, sobretudo a internet dos dias atuais. O autor reforça que a tecnologia promove uma integração de espaços e tempos, proporcionando um ensinoaprendizagem numa sala de aula estendida, ou seja, presencialmente e por meio digital. 
Quando se fala em ensino superior - foco nesta discussão -, por meio do qual preparamse pessoas para serem profissionais qualificados, continuará a se insistir na aula expositiva, enquanto o mercado de trabalho exige mão de obra com amplo conhecimento tecnológico, nas mais diversas áreas?

A partir desses questionamentos, entende-se que é preciso promover debates, de modo que se busquem respostas e estratégias que mostrem novos caminhos para que professores e instituições possam seguir, a fim de atrair a atenção dos alunos e tornálos mais capacitados para o mundo profissional. Nesse contexto, conforme evidenciam Paiva et al. (2016, p. 146) "[...] as tendências do século XXI indicam que a característica central da educação é o deslocamento do enfoque individual para o enfoque social, político e ideológico".

O que referidos autores colocam em reflexão é a necessidade de uma educação que promova uma relação diferenciada com o estudante, num relacionamento coletivo, mas também individualizado, conforme sua vivência, adequando-a à pedagogia. Isso inclui mudar o formato educacional como um todo e o papel docente em sala de aula; foi o que fez uma Faculdade de Santa Catarina com seu grupo de mais de 200 professores.

Com o intuito de prepará-los para mudanças na sala de aula de cursos presenciais e torná-los aptos a atuarem em cursos na modalidade a distância, a Instituição de Ensino Superior (IES) organizou uma especialização exclusiva para seus professores e técnicosadministrativos. Intitulada de 'Educação a Distância: docência e tutoria', o curso busca dar ênfase aos estudos a partir das metodologias ativas de aprendizagem que propositam modificar os papeis de alunos e docentes, transformando tanto a estruturação da sala de aula quanto as práticas do processo de ensino-aprendizagem. Essas metodologias apontam para "[...] a possibilidade de transformar aulas em experiências de aprendizagens mais vivas e significativas para os estudantes da cultura digital" (ALMEIDA, 2018, p. 12).

Neste sentido, a primeira aula prática da especialização tornou-se um divisor de águas para a nova IES que recém se formava. O relato da experiência dessa aula é o foco desse artigo, conforme discutiremos mais adiante, o qual tem como objetivo maior contribuir com discussões sobre um formato mais ativo no processo de ensinoaprendizagem no ensino superior.

\section{Referencial teórico}

Os métodos de ensino-aprendizagem não são estagnados e devem ser modificados no 
mesmo compasso da evolução da sociedade. Na atualidade, a tecnologia tem interferido na vivência humana e, consequentemente, na educação. Um grande exemplo está no Ensino a Distância (EaD) que tem garantido cada vez mais o seu espaço nas mais diversas esferas educacionais.

A história revela que o marco inicial dessa modalidade de ensino deu-se em 1728, quando a Gazeta de Boston passou a ofertar um curso por meio de correspondências. $\mathrm{Na}$ atualidade, os dados sobre cursos em EaD e instituições que investem nessa modalidade só crescem. Já são mais de 80 países que fazem uso do EaD nos diferentes níveis educacionais (ALVES, 2011).

Não há como negar que o $\mathrm{EaD}$ consegue atingir públicos abrangentes e que antes possuíam pouco acesso ao ensino superior, tanto por questões geográficas, quanto por falta de tempo e dinheiro. Enquanto cursos presenciais tendem a ter encontros diários e custos mais elevados, o EaD oferece uma ampla gama de cursos, com encontros presenciais muitas vezes apenas uma vez na semana, e com valores financeiros bem mais acessíveis.

Além disso, a tecnologia tem contribuído com o formato que os conteúdos são apresentados aos alunos. De aulas por meio de correspondências e rádio para aulas por vídeos, webconferências, fóruns on-line, livros digitais, recursos gamificados e apresentações interativas. Com essas transformações, o acesso ao conhecimento ficou mais interessante, conforme destaca Almeida (2018, p. 9), quando diz que "a intensa expansão do uso social das tecnologias digitais de informação e comunicação (TDIC) sob a forma de diferentes dispositivos móveis conectados à Internet sem fio, utilizados em diferentes espaços, tempos e contextos, observada na segunda década do século $X X I$, gerou e continua gerando mudanças sociais que provocam a dissolução de fronteiras entre espaço virtual e espaço físico e criam um espaço híbrido de conexões".

Contudo, quando se fala em aula - e isso inclui tanto os cursos na modalidade EaD quanto os presenciais -, ainda se priorizam as metodologias tradicionais, com professor (e tutor) que passam explicações expositivas e não exploram o espaço e o momento para promoverem discussões e reflexões melhores.

Frente aos desafios desse novo tempo é que entram as chamadas metodologias ativas de aprendizagem. Diversos teóricos e professores têm, nos últimos tempos - apesar de o termo ainda ser novo -, colocado em evidência a necessidade de sair do comum e buscar novos recursos para a sala de aula. As metodologias ativas são propostas para novos formatos educacionais, principalmente na relação entre docente e aluno, aluno e 
aluno. Nesta proposta, "[...] o professor deve adotar a perspectiva do aluno, deve acolher seus pensamentos, sentimentos e ações, sempre que manifestados, e apoiar 0 seu desenvolvimento motivacional e capacidade para autorregular-se" (BERBEL, 2011, p. 28).

Enquanto o ensino mais tradicional tem o professor como o detentor do conhecimento, que faz uso da 'sua aula' para repassar as informações, normalmente por meio de slides e escritos em quadro branco, as metodologias ativas de aprendizagem colocamno como um mediador do conhecimento; ou seja, muito mais do que expositor, ele contribui com a aula a partir de estratégias que colocam o aluno como o principal protagonista da sua própria aprendizagem.

Com as metodologias ativas, o docente proposita que o aluno seja mais dinâmico, autônomo e responsável pelo seu conhecimento. É ele quem deve descobrir o conteúdo, ser livre e independente para formar a sua melhor maneira de estudar - como o EaD digital já oferece. Neste processo, contribui-se para estimulá-lo nessa busca, tornandose o professor em uma espécie de referência com quem o aluno pode confiar, tirar dúvidas e buscar conteúdos complementares ao que aprende. A esse respeito, Morán (2015, p. 17) ressalta que "se queremos que os alunos sejam proativos, precisamos adotar metodologias em que [...] se envolvam em atividades cada vez mais complexas, em que tenham que tomar decisões e avaliar os resultados, com apoio de materiais relevantes. Se queremos que sejam criativos, eles precisam experimentar inúmeras novas possibilidades de mostrar sua iniciativa".

Frente ao exposto, destaca-se que a literatura coloca como referência diversas metodologias ativas de aprendizagem como, por exemplo: Estudo de Caso, Aprendizagem Baseada em Problemas, Aprendizagem Baseada em Projetos, Peer Instruction, dentre outras. Em muitas delas, a tecnologia se faz presente e se torna um recurso fundamental para se fazer da aula algo mais dinâmico e que tenho o aluno como centro principal.

A seguir, discorremos sobre uma dessas metodologias ativas, por meio de um relato de experiência em uma IES do Estado de Santa Catarina.

\section{Apresentação e discussão dos resultados}

A Faculdade Avantis, localizada no município de Balneário Camboriú, litoral norte de Santa Catarina, possui 15 anos de existência e mais de 15 cursos presenciais, com mais de quatro mil alunos. Nos últimos anos, vem diagnosticando a necessidade de mudar 
sua metodologia pedagógica em sala de aula, em virtude da percepção de se investir em aulas mais dinâmicas e focadas na aprendizagem dos alunos, bem como para que seus professores sejam capacitados permanentemente a fazerem melhor uso das tecnologias no processo de ensino-aprendizagem.

A partir de 2017, com um planejamento iniciado para a abertura de diversos cursos na modalidade a distância, os gestores de referida IES perceberam a necessidade de capacitar o quadro docente para essas constantes e ubíquas mudanças. Foi então quando se idealizou um curso de especialização, oferecido gratuitamente a todos os docentes e técnicos-administrativos, com o tema 'Educação a Distância: docência e tutoria'. Referido curso buscou, de início, prepará-los para o formato que se exige legalmente para atuação em EaD, como o papel do tutor e outras funções fundamentais da estrutura técnica e pedagógica de um curso a distância. Porém, também foi planejado para provocar mudanças culturais dos professores, muitos deles acostumados com o ensino tradicional e 'bancário', por assim dizer.

Neste sentido, a primeira disciplina disponibilizada - convém destacar que a especialização ocorreu em EaD, com um encontro presencial por disciplina - foi a de Metodologias Ativas de Aprendizagem, com o intuito de provocar uma espécie de 'choque de pensamentos e reflexões' sobre como estavam atuando em sala de aula e as mudanças que deveriam fazer nessa nova perspectiva educacional.

Os conteúdos foram expostos no Ambiente Virtual de Aprendizagem (AVA), antes do encontro presencial, para que pudessem ser acessados e explorados de maneira mais significativa durante a aula que sempre iniciava com uma parte expositiva e depois promovida uma prática. No entanto, essa situação fez surgir o principal desafio: Como ministrar uma aula prática para aproximadamente duzentos alunos ao mesmo tempo?

O melhor caminho encontrado pelos gestores foi fazer uso das metodologias ativas de aprendizagem, principal ponto de discussão dessa disciplina. Desta forma, ao fazer uma análise minuciosa de diversas possibilidades discutidas na literatura e expostas no conteúdo teórico, optou-se pelo uso da Rotação por Estações.

Entende-se esse tipo de metodologia ativa uma oportunidade de apresentar mais de uma ferramenta para a aprendizagem em sala de aula, contribuindo com um encontro mais dinâmico, visto que os alunos se movimentam entre as estações, cumprindo as atividades propostas. Bacich e Morán (2015, p. 45 e 46) explicam acerca dessa prática, afirmando que: 
Os estudantes são organizados em grupos, e cada um desses grupos realiza uma tarefa de acordo com os objetivos do professor para a aula. Um dos grupos estará envolvido com propostas on-line que, de certa forma, independem do acompanhamento direto do professor. É importante notar a valorização de momentos em que os alunos possam trabalhar colaborativamente e momentos em que trabalhem individualmente. Após determinado tempo, previamente combinado com os estudantes, eles trocam de grupo, e esse revezamento continua até que todos tenham passado por todos os grupos. As atividades planejadas não seguem uma ordem de realização, sendo de certo modo independentes, embora funcionem de maneira integrada para que, ao final da aula, todos tenham tido a oportunidade de ter acesso aos mesmos conteúdos.

Para a aula relatada nesse estudo, foi importante pensar além dos conteúdos abordados, mas também na estrutura como seria organizada essa prática, levando-se em conta o grande número de estudantes. Diante o exposto, o local escolhido foi o ginásio de esportes da IES, o qual acabou por ser dividido em quatro partes distintas. Várias carteiras e cadeiras de sala de aula foram expostas nos espaços, conforme a necessidade que cada atividade previa. O uso da tecnologia se fez presente na dinâmica, portanto, também foi necessário disponibilizar notebooks, tablets e acesso às tomadas elétricas.

A definição dos objetivos de aprendizagem de cada estações aconteceu a partir dos conteúdos que seriam abordados e com quais estratégias esses conteúdos poderiam ser melhores explorados. Desta forma, a organização ficou assim dividida: Estação 1: criação de apresentações em Power Point sobre Ensino Híbrido; Estação 2: criação de uma Análise SWOT para avaliar os pontos fracos e fortes da inserção de metodologias ativas de aprendizagem e ensino híbrido na Instituição de Ensino em questão, bem como as oportunidades e ameaças advindas com essa nova prática; Estação 3: criação de um vídeo, com celular ou tablet, sobre o papel docente diante dessa nova pedagogia que preza por metodologias mais ativas e; por fim, Estação 4: criação de um mapa conceitual sobre ensino híbrido, de acordo com a leitura prévia de um livro disposto no AVA.

Para a circulação entre as estações foram formados 20 grupos de 10 pessoas. A proposta era de que cinco grupos ficassem em cada estação ao mesmo tempo. A comunicação com todos os alunos ocorreu por microfone pelo professor titular da disciplina, que cronometrava e informava quando era preciso mudar de ambiente. As atividades duravam em torno de 20 minutos, cada.

Imagem 1 - Alunos divididos nas estações 


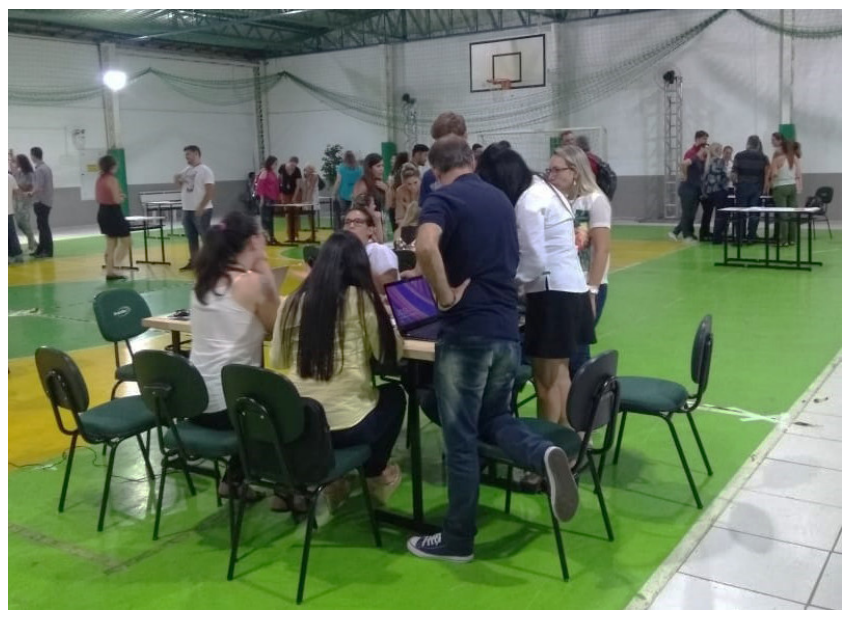

Fonte: Acervo dos autores

Devido ao número de alunos, percebeu-se ser importante que o professor oferecesse um apoio em cada estação; para isso, outros professores do curso de pós-graduação, que auxiliaram na organização e no desenvolvimento da ideia da prática, dividiram-se entre os grupos e todas as dúvidas eram a eles dirigidas.

principal objetivo dessa aula foi demonstrar na prática como se pode levar as metodologias ativas de aprendizagem para a sala de aula, independentemente da área de formação. Com essa ação, os alunos - professores e colaboradores - viram na teoria a importância dessas metodologias, mas por ser algo novo na educação, também era fundamental que tivessem a oportunidade de as experienciarem, afinal, "[...] tem ficado cada vez mais claro que apenas o domínio do conteúdo - embora seja fundamental no processo de ensino e aprendizagem - não é suficiente" (SANTOS, 2018, p. 21).

Em uma única aula, os 'professores-alunos' tiveram a oportunidade de compreenderem como aplicar a metodologia das 'Rotações por Estações', contudo também se colocaram diante de outras quatro estratégias, trabalhadas em cada uma das estações. A criação das apresentações em Power Point sobre os principais conceitos trabalhados nesse módulo exigiu o uso de notebooks, aula que pode ser preparada em um laboratório de informática, por exemplo. Enquanto a Análise SWOT, conceito que vem da Administração e do Marketing, pode ser feita com cartolinas e post-its.

Por meio da inclusão da estação da gravação do vídeo observou-se que esse recurso é profícuo ao processo de ensino-aprendizagem; vez que tanto pode ser explorado pelo professor, que com um simples celular consegue preparar a explicação de um conteúdo, quanto pelos alunos, a partir de atividades que o docente propõe com a gravação feita por eles. 
Imagem 2 - Registro de uma mapa conceitual produzido pelos alunos

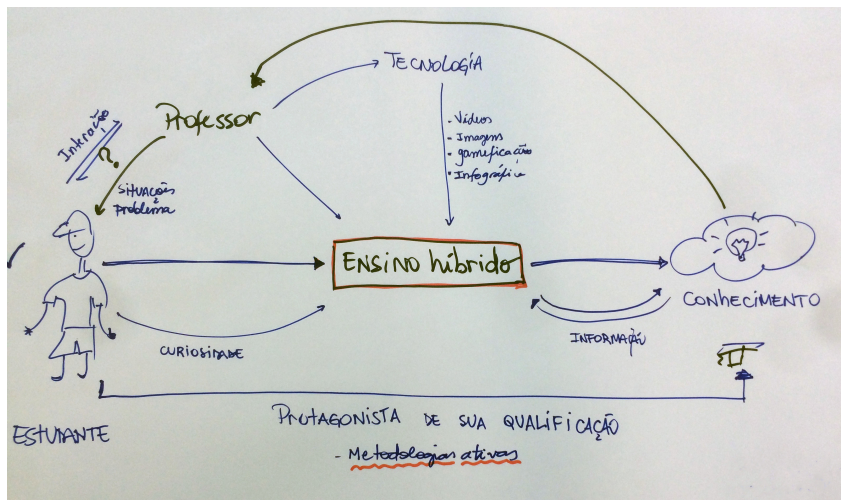

Fonte: Acervo dos autores

Por último, o mapa conceitual também foi avaliado pelos 'professores-alunos' como uma metodologia ativa de aprendizagem a ser incorporada em suas práxis, sendo que 0 mesmo também pode ser feito digitalmente, já que existem diversos softwares que auxiliam na criação gráfica; caso não for possível, pode-se contar com folhas de papel ou cartolina. Contudo, verificou-se que o uso essa metodologia é uma maneira de ampliar o conhecimento acerca dos conteúdos pela capacidade de entendimento e sintetização das informações pelos alunos.

Os resultados dos trabalhos, conforme percepção de avaliação dos professores, demonstrou o entendimento dos alunos por parte do que é ensino híbrido, das possibilidades de metodologias ativas para uso nas práticas pedagógicas e do conhecimento sobre diversas ferramentas que contribuem com a acesso ao conhecimento. "O envolvimento dos alunos, que são professores da casa, durante as atividades mostraram a eficácia da proposta, bem como os comentários de que levariam determinada metodologia para suas aulas", relatou um dos docentes responsáveis pela estratégia.

\section{Considerações finais}

O resultado dessa experiência revelou um importante envolvimento por parte dos estudantes da pós-graduação. O depoimento de muitos veio ao encontro da proposta das atividades: conseguiram compreender na prática os conceitos e as usabilidades das metodologias ativas de aprendizagem. Tal experiência possibilitou que os próprios professores se colocassem no papel de seus alunos e entendessem o quanto esse modelo de aula é mais atrativo, interessante e eficiente, vez que é possível 'se aprender, brincando'. Ademais, ficou evidente aos professores da IES que os antigos 
modelos de metodologias de ensino-aprendizagem precisam ser revistos, repensados constantemente e adequados às novas exigências dos alunos que carecem e esperam por uma nova escola.

No decorrer do semestre letivo após essa aula prática, registraram-se diversas metodologias ativas sendo aplicadas em sala pelos professores que participaram dessa formação. Os resultados são por eles compartilhados em uma plataforma digital, o que demonstra a eficácia gerada por essa iniciativa relatada, que propositou um novo marco no processo de ensino-aprendizagem na IES pesquisada.

\section{Referências}

ALMEIDA, M. E. B. Apresentação. In: BACICH, L.; MORÁN, J. Metodologias ativas para uma educação inovadora: uma abordagem teórico-prática. Porto Alegre: Penso, 2018. P. 9-13.

ALVES, L. Educação a Distância: conceitos e história no Brasil e no mundo. Revista Brasileira de Aprendizagem Aberta e a Distância. v. 10, 2011.

BACICH, L.; MORAN, J.M. Aprender e ensinar com foco na educação híbrida. In.: Rev. Pátio, n.25, p..45-47, 2015.

BERBEL, N. A. N. As metodologias ativas e a promoção da autonomia de estudantes. In.: Ciências Sociais e Humanas, Londrina, v. 32, n. 1, p. 25-40, jan.jun. 2011.

MORAN, J. M. Mudando a educação com metodologias ativas. Convergências midiáticas, educação e cidadania: aproximações jovens. Ponta Grossa: UEPG Foca, 2015.

PAIVA, M. R., et. al. Metodologias ativas de ensino-aprendizagem: revisão integrativa. In.: Sanare, 15(2), 2016, p. 143-153.

SANTOS, Ariovaldo dos. Apresentação. In: LEAL, E. A; MIRANDA, G. J.; NOVA; S. P. C. C. Revolucionando a sala de aula: como envolver o estudante aplicando as técnicas de metodologias ativas de aprendizagem. São Paulo: Atlas, 2018. p. 21-24. 